\title{
The Relationship between the Morphology and Elasticity of Natural Rubber Foam Based on the Concentration of the Chemical Blowing Agent
}

\author{
Supitta Suethao ${ }^{1}$, Saree Phongphanphanee ${ }^{1}$, Jirasak Wong-ekkabut ${ }^{1,2}$ and Wirasak Smitthipong ${ }^{1,3, *}$ \\ 1 Specialized Center of Rubber and Polymer Materials in Agriculture and Industry (RPM), Department of \\ Materials Science, Faculty of Science, Kasetsart University, Bangkok 10900, Thailand; \\ supitta.sue@gmail.com (S.S.); fscisrph@ku.ac.th (S.P.); fscijsw@ku.ac.th (J.W.-e.) \\ 2 Department of Physics, Faculty of Science, Kasetsart University, Bangkok 10900, Thailand \\ 3 Office of Research Integration on Target-Based Natural Rubber, National Research Council of \\ Thailand (NRCT), Bangkok 10900, Thailand \\ * Correspondence: fsciwssm@ku.ac.th
}

check for updates

Citation: Suethao, S.;

Phongphanphanee, S.; Wong-ekkabut, J.; Smitthipong, W. The Relationship between the Morphology and Elasticity of Natural Rubber Foam Based on the Concentration of the Chemical Blowing Agent. Polymers 2021, 13, 1091. https://doi.org/ $10.3390 /$ polym 13071091

Academic Editor: José Ignacio Velasco

Received: 27 February 2021

Accepted: 25 March 2021

Published: 30 March 2021

Publisher's Note: MDPI stays neutral with regard to jurisdictional claims in published maps and institutional affiliations.

Copyright: (c) 2021 by the authors. Licensee MDPI, Basel, Switzerland. This article is an open access article distributed under the terms and conditions of the Creative Commons Attribution (CC BY) license (https:// creativecommons.org/licenses/by/ $4.0 /)$.

\begin{abstract}
Concentrated natural latex was used to produce a rubber foam that is porous, elastic and well ventilated. The mechanical properties can be either soft or firm, depending on the formulation of the latex used. Briefly, concentrated natural latex was mixed with chemical agents to make the rubber foam on a laboratory scale using the Dunlop process. In this work, we changed the concentration of the chemical blowing agent in the latex. The morphological properties of the rubber foam were characterised using scanning electron microscopy, and the mechanical properties, or elasticity, were studied using compression experiments and the Mooney-Rivlin calculation. The results show that the concentration of the chemical blowing agent affects the morphological properties of the rubber foam but not the mechanical properties, indicating the heterogeneous structure of the rubber foam. The thermodynamic parameters $(\Delta G$ and $\Delta S$ ) and the internal energy force per compression force $\left(F_{\mathrm{u}} / F\right)$ of the rubber foam with various amounts of chemical blowing agent were also investigated. This study could be applied in the foam industry, particularly for pillow, mattress and insulation materials, as the present work shows the possible novel control of the morphological structure of the rubber foam without changing its mechanical properties. The difference in cell sizes could affect the airflow in rubber foam.
\end{abstract}

Keywords: rubber foam; morphology; elasticity; thermodynamics; chemical blowing agent

\section{Introduction}

Natural rubber foam (NR foam) is a good example of a long-chain polymer with great elasticity. It also possesses excellent mechanical properties with different morphological properties. NR foam is a lightweight material with many porous structures, indicating a good compromise between strength and weight [1,2]. NR foam is prepared from both concentrated natural latex and non-latex rubber [3,4]. It has been used for many years to produce many products, such as mattresses, pillows, dolls, cushions, flooring and upholstery foam [5-8]. Many processes are used in rubber foam production, but the most popular process is the Dunlop process. The Dunlop process is a trendy process used to produce foam rubber with open-cell morphology [9].

The previous works focused on varying concentrations of sodium bicarbonate as a chemical blowing agent in natural rubber foam [10,11]. However, these works studied different types of natural rubber: concentrated natural latex and dried natural rubber. They found that the relative density of both types of NR foam decreased with increased amounts of chemical blowing agent. The cell density increased with increased amounts of the chemical blowing agent. Moreover, the compression strength of NR foam from latex tended to decrease with increasing chemical blowing agent concentrations, while the 
NR foam from dried rubber with higher chemical blowing agent concentrations absorbed more energy. Since more of the air bubble from chemical blowing agent is presented, the rubber foam reveals softer. The existence of the air bubble in rubber foam exhibits the energy-absorbing characteristic of foam.

The effects of cell size and the interconnected matrix (or cell wall thickness) on the Young's modulus of closed-cell foams made of styrene-acrylonitrile were studied using Laguerre models. The results showed that the stiffness decreased with increasing cell size, so the stiffness of polymer foams related to the cell size distribution and interconnected matrix was investigated [12,13]. The influence of the foaming condition on the cellular structure of poly(methyl methacrylate) (PMMA) foam has been studied by varying the $\mathrm{CO}_{2}$ pressure and temperature. The production of PMMA foams with control structures was prepared by using $\mathrm{CO}_{2}$ as the physical blowing agent. The results showed that the largest void fraction of PMMA foam, with a cell size of less than $5 \mu \mathrm{m}$, could be produced, improving the thermal and mechanical properties of PMMA foam.

The main properties of rubber foam are low weight, high buoyancy, cushioning capability, flexibility, thermal insulation, acoustic insulation and impact dampening [11,14]. Because of this great variety of properties, rubber foam can be used in many applications. Many researchers have studied the factors affecting these properties. However, little work has been done to understand the effect of the chemical blowing agent on the morphology and elasticity of foams. A thermodynamic investigation of rubber foam from concentrated natural latex is particularly lacking. The novelty of this work is to reveal the relationship of the morphology, elasticity and thermodynamic properties of rubber foam to the effects of the chemical blowing agent, developing a semi-empirical model to design the NR foams with different microscale morphological structures but unchanged macroscale mechanical properties.

\section{Materials and Methods}

\subsection{Materials}

Commercial high ammonia (HA) concentrated natural latex was obtained from Num Rubber and Latex Co., Ltd., Trang, Thailand. An aqueous solution of $10 \%$ potassium oleate (Po) and aqueous dispersions of 50\% sulphur, $50 \%$ zinc-N-diethyldithiocarbamate (ZDEC), 50\% zinc-2-mercaptobenzothiazole (ZMBT), 50\% antioxidant (Wingstay L), 50\% zinc oxide (ZnO), 33\% diphenylguanidine (DPG) and 12.5\% sodium silicofluoride (SSF) were supplied from Thanodom Technology Co., Ltd., Bangkok, Thailand.

\subsection{Preparation of Compounded Latex}

To prepare the compounded latex, the ammonia in the concentrated natural latex was evaporated by blending at a low speed $(80 \mathrm{rpm})$ for $1 \mathrm{~min}$. Then, various concentrations of Po in an aqueous solution were added, and the blender speed was increased to $160 \mathrm{rpm}$ for $8 \mathrm{~min}$ or the time needed to achieve a bubble volume of 3.5 L. Next, the aqueous dispersions of sulphur, ZDEC, ZMBT and antioxidant (Wingstay L) were added, and the speed was decreased to $80 \mathrm{rpm}$ for $1 \mathrm{~min}$. After that, the aqueous dispersions of $\mathrm{ZnO}$ and DPG were added and mixed for a further $1 \mathrm{~min}$. Finally, the aqueous dispersion of SSF was added and mixed until the gel-forming state was reached (Table 1 and Table S1).

\subsection{Preparation of Rubber Foam}

To prepare the rubber foam, the compounded latex was poured into a stainless-steel mould, which was $50 \mathrm{~mm}$ in width, $50 \mathrm{~mm}$ in length, and $25 \mathrm{~mm}$ in height. Then, the mould was kept at room temperature for $45 \mathrm{~min}$ to stabilise the bubbles. Next, the mould was moved to a $90^{\circ} \mathrm{C}$ oven for $2 \mathrm{~h}$ to vulcanise the rubber foam. Finally, the rubber foam was removed from the mould, washed, and dried in an oven at $70^{\circ} \mathrm{C}$ for $4 \mathrm{~h}$. 
Table 1. Formulas of rubber foams at various chemical blowing agents: control sample, control sample with decreasing Po at $15 \%$ (control - 15\% Po), control sample with decreasing Po at 30\% (control - 30\% Po), and control sample with decreasing Po at $45 \%$ (control $-45 \%$ Po).

\begin{tabular}{|c|c|c|c|c|}
\hline Chemical Agents & Control (g) & Control - 15\% Po (g) & Control - $30 \%$ Po (g) & Control - 45\% Po (g) \\
\hline $60 \%$ concentrated natural latex & 166.67 & 166.67 & 166.67 & 166.67 \\
\hline $10 \%$ potassium oleate aqueous solution $(\mathrm{Po})$ & 16.50 & 14.00 & 11.50 & 9.00 \\
\hline $50 \%$ sulphur aqueous dispersion & 4.00 & 4.00 & 4.00 & 4.00 \\
\hline $50 \%$ ZDEC aqueous dispersion & 2.00 & 2.00 & 2.00 & 2.00 \\
\hline $50 \%$ ZMBT aqueous dispersion & 2.00 & 2.00 & 2.00 & 2.00 \\
\hline $50 \%$ antioxidant (Wingstay L) aqueous dispersion & 2.00 & 2.00 & 2.00 & 2.00 \\
\hline $50 \% \mathrm{ZnO}$ aqueous dispersion & 10.00 & 10.00 & 10.00 & 10.00 \\
\hline $33 \%$ DPG aqueous dispersion & 2.00 & 2.00 & 2.00 & 2.00 \\
\hline $12.5 \%$ SSF aqueous dispersion & 8.00 & 8.00 & 8.00 & 8.00 \\
\hline
\end{tabular}

\subsection{Characterisation}

The morphological properties of the foam samples were evaluated by scanning electron microscopy (SEM, Quanta $450 \mathrm{FEI}$, Eindhoven, Netherlands). The rubber foam (surface and bulk) was cut into small samples and coated with gold in a special coater (Polaron Range SC7620, Quorum Technologies Ltd., Kent, UK). ImageJ software [15] was used to analyse SEM images and calculate cell sizes and porosity. Cell density can be calculated following the previous work [16]. Foam density was measured in $\mathrm{kg} / \mathrm{m}^{3}$ using the weight at a constant volume of foam sample.

Chemical functional groups of the foam samples were analysed by attenuated total reflection-Fourier transform infrared spectroscopy (ATR-FTIR, VERTEX 70, Bruker, Billerica, MA, USA) with a Ge crystal probe at $500-4000 \mathrm{~cm}^{-1}$.

Mechanical properties of foam samples in compression mode were characterised by a texture analyser (TA.XT Plus, Stable Micro Systems, Godalming, Surrey, UK) using a $100 \mathrm{~mm}$ diameter platen probe with a speed of $0.1 \mathrm{~mm} / \mathrm{s}$ and compressed at $75 \%$ from the foam surface at room temperature. Moreover, we applied the Mooney-Rivlin equation [17] at the stress $(\sigma)$ and compression limit $(\lambda)$ of foam samples with $C_{1}$ and $C_{2}$ as constant values as follows:

$$
\frac{\sigma}{\left(\lambda-\frac{1}{\lambda^{2}}\right)}=2 C_{1}+2 C_{2} \frac{1}{\lambda}
$$

The crosslinking density and volume fraction of the rubber foam samples were determined by the swelling method and the Flory-Rehner equation [18-20]. We also used the Flory-Huggins equation to calculate the change in Gibbs free energy $(\Delta G)$ and entropy $(\Delta S)$ as follows [21,22]:

$$
\begin{gathered}
\Delta G=R T\left[\ln \left(1-V_{\mathrm{r}}\right)+V_{\mathrm{r}}+V_{\mathrm{r}}^{2} \mathcal{X}\right] \\
S=\frac{\Delta G}{T}
\end{gathered}
$$

where $V_{\mathrm{r}}$ is the volume fraction of the foam sample in the rubber network, $\chi$ is the parameter between the foam sample and the solvent interaction (defined as $0.43+0.05$ $V_{\mathrm{r}}$ ) [23], $R$ is the ideal gas constant $(8.3145 \mathrm{~J} / \mathrm{mol} \cdot \mathrm{K})$, and $T$ is the test temperature $(298.15 \mathrm{~K})$.

The foam sample was evaluated using a texture analyser (TA.XT Plus, Stable Micro Systems, Godalming, Surrey, UK) using a speed of $0.1 \mathrm{~mm} / \mathrm{s}$. The sample was held for $10 \mathrm{~min}$ to ensure a constant temperature. The foam sample was then compressed from $10 \%$ strain to $70 \%$ strain at different temperatures $(298.15,308.15,318.15,328.15$ and $338.15 \mathrm{~K})$. Then, the force-temperature relationship graph during the deformation process was determined, and the parameters obtained were used to calculate the internal energy force $\left(F_{\mathrm{u}}\right)$ from the intercept at $0 \mathrm{~K}$ and the entropy force $\left(F_{\mathrm{s}}\right)$ from the slope multiplied by the temperature. 


\section{Results and Discussion}

The effect of the chemical blowing agent (potassium oleate) on foam rubber was studied in this work by varying the potassium oleate concentration. In this study, foam rubber was prepared with varying concentrations of the chemical blowing agent $(0.90$, $1.15,1.40$ and $1.65 \mathrm{phr}$ or parts per hundred of rubber as in Table S1) corresponding to the control - $45 \%$ Po, the control - $30 \%$ Po, the control - 15\% Po and the control. Thus, the chemical blowing agent concentration at $1.65 \mathrm{phr}$ is the control formula (Table S1), and the concentration has been decreased to study the effect of the chemical blowing agent on the morphological properties and elasticity of the rubber foam.

\subsection{Morphological and Physical Properties}

The morphological properties of all the foam samples are illustrated in Figure 1, showing the effect of the chemical blowing agent (potassium oleate) on morphology. There were two structures-pores or cells_-representing the void space and cell wall thickness, making up the interconnected foam matrix. The cells were generally interconnected with each other, an open-cell structure. This structure comes from the Dunlop preparation method, which mixes the latex at high speed, generating different sizes of gas bubbles $[24,25]$. The open-cell structure with connected foam cells can occur with gas bubbles of either the same or different sizes. When two gas bubbles are near each other, the gas can transfer from the smaller bubble to the larger bubble, resulting in the bubbles merging to become an open-cell structure [26,27]. As the chemical blowing agent concentration decreased, micrographs showed more interconnected foam structures with smaller cell sizes than those of the control sample. However, the morphological structure of polymer foam can be made either open cell or closed cell [28]. William and Wrobleski investigated the effect of surfactantstabilised HIPE (high internal phase emulsions) on polyHIPE foam properties [29]. They found that this polymer foam has a closed-cell structure at a surfactant content below $7 \mathrm{vol} \%$, but beyond this concentration, the polymer foam has an open-cell structure.

Figure 2 shows SEM images of all the foam samples processed using the ImageJ software, where the black colour indicates the foam cell and the white colour means interconnected matrix. We calculated the average cell size and porosity of the foam samples using these images, and the results are shown in Table 2. We found that the average cell size of the foam samples decreases with decreasing potassium oleate concentration because smaller gas bubbles were generated. The overall porosity of the foam samples seems to increase with decreasing chemical blowing agent, indicating the effect of smaller and larger gas bubble distributions in the foam matrix. Low concentrations of chemical blowing agent in foam samples generated small gas bubbles resulting in high cell density. The morphology of surface and bulk foam samples was similar, based on the heterogeneous cell size generated by the Dunlop process. The relationship between the average cell size and the blowing agent concentration in this work is in good agreement with previous research [30]. Both works used chemical blowing agent concentrations below $3 \mathrm{wt} \%$. However, the opposite relationship of cell size and blowing agent concentration was reported in polysulfone (PSU) foam [31]: the average cell size decreased with an increase in the physical blowing agent, a $\mathrm{CO}_{2}$ feed at high concentrations in the PSU. The morphology of the polymer foam depends on the foam preparation method and the type of blowing agent. The computer models based on self-consistent field theory (SCFT) and classical nucleation theory (CNT) propose a model of the best polymer foam with simultaneous small cell size and high cell density [32]. 


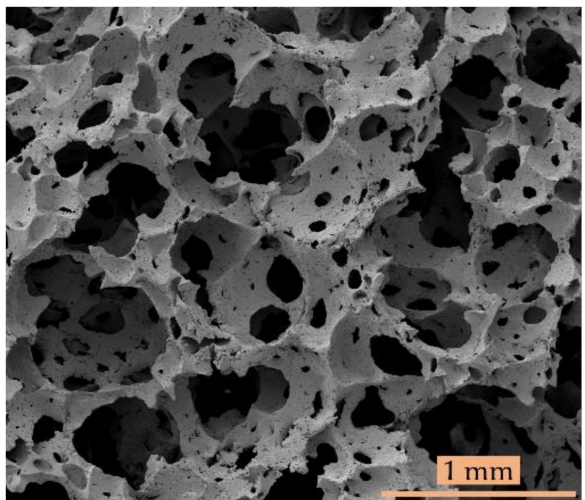

(a)

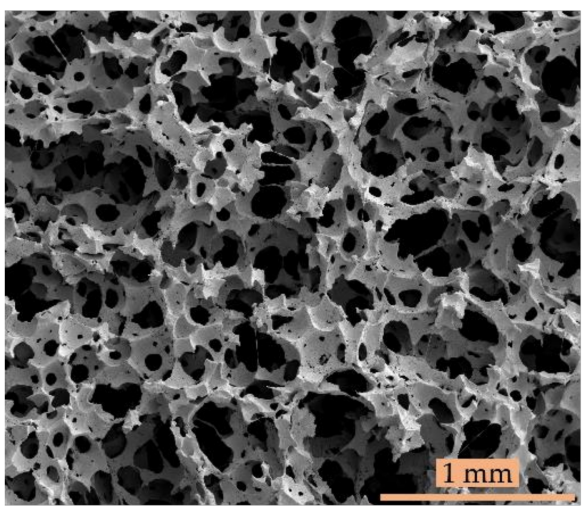

(C)

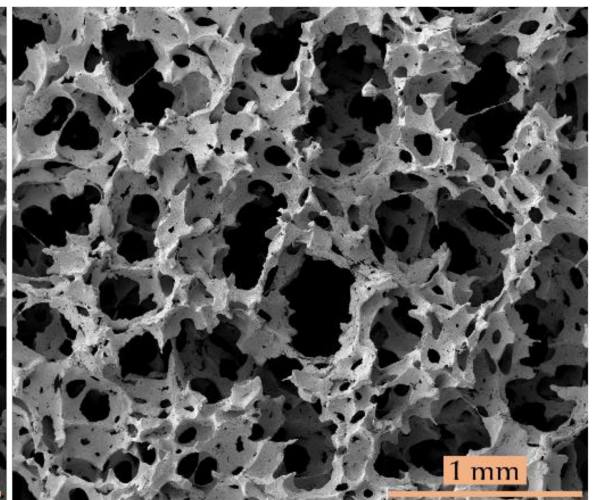

(b)

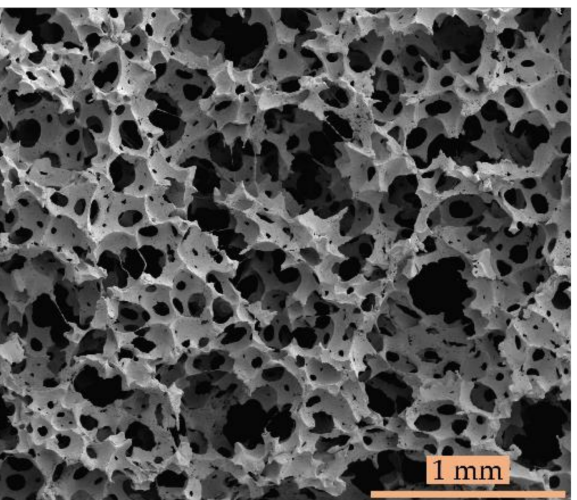

(d)

Figure 1. SEM images of foams created with various concentrations of chemical blowing agent at $150 \times$ magnification: (a) control foam, (b) control - 15\% Po foam, (c) control - 30\% Po foam, and (d) control - $45 \%$ Po foam.

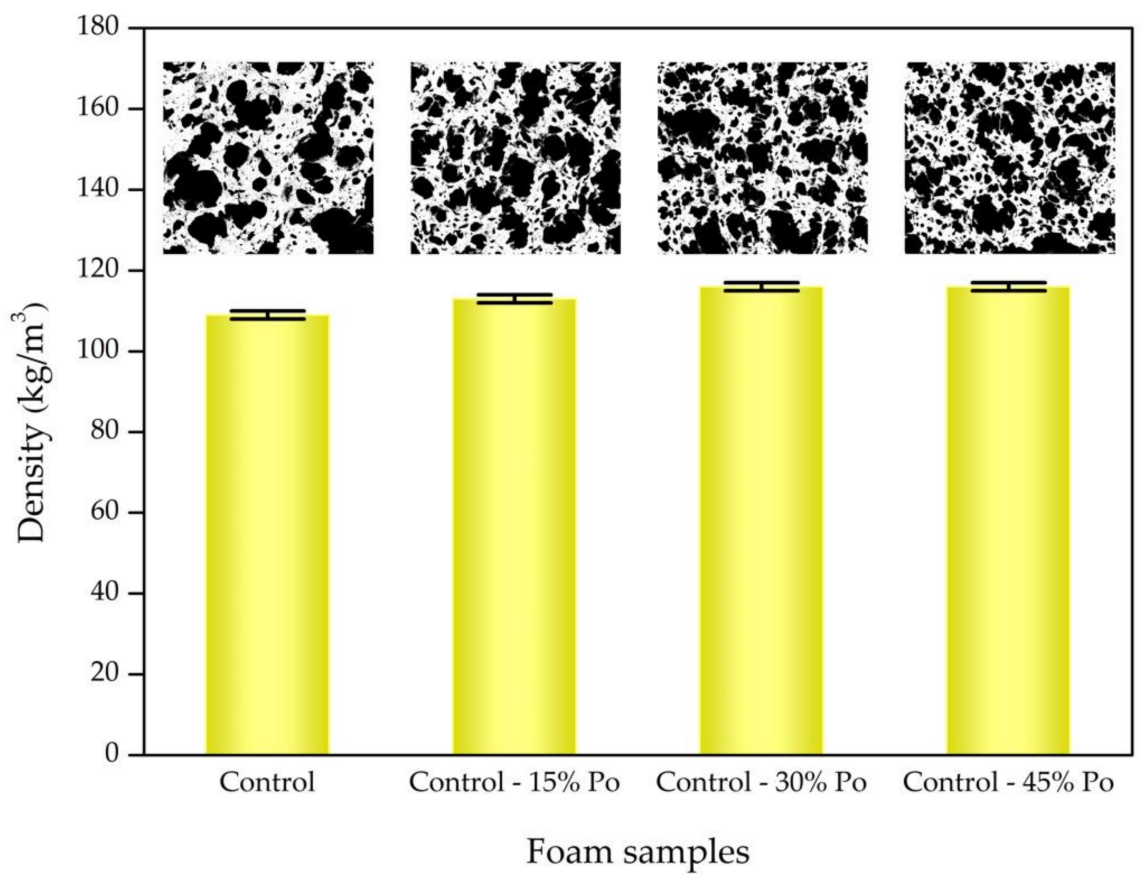

Figure 2. SEM images analysed by ImageJ software and foam density as a function of foam samples with different concentrations of the chemical blowing agent. 
Table 2. Morphological characteristics of various foam samples: cell size and porosity were determined by analysing the SEM images with ImageJ. The cell density was calculated using the same method in previous work [33].

\begin{tabular}{cccc}
\hline Sample & $\begin{array}{c}\text { Average Cell Size } \\
( \pm \mathbf{1 5 0} \boldsymbol{\mu \mathbf { m } )}\end{array}$ & Porosity $( \pm \mathbf{1 . 0 0} \mathbf{)})$ & $\begin{array}{c}\text { Cell Density } \\
\left( \pm \mathbf{5 0 0} \mathbf{~ c m}^{-3}\right)\end{array}$ \\
\hline Control & 548 & 49.86 & 10,241 \\
Control - 15\% Po & 473 & 54.73 & 15,908 \\
Control - 30\% Po & 320 & 56.06 & 50,837 \\
Control - 45\% Po & 273 & 54.78 & 82,450 \\
\hline
\end{tabular}

To investigate the physical properties of rubber foams, foam density results are presented in Figure 2. Lower blowing agent concentrations free the gas to escape through the foam surface, allowing the foam to condense more, and consequently, foam with a slightly higher density is produced. However, it seems that a constant foam density is reached at blowing agent concentrations below $70 \%$ or $1.15 \mathrm{phr}$. The rubber foam with chemical blowing agent concentrations above $1.65 \mathrm{phr}$ has a foam density similar to the control sample (chemical blowing agent concentration of $1.65 \mathrm{phr}$ ). This result tends to agree with the foam densities of various chemical blowing agent (i.e., sodium bicarbonate) concentrations in dried natural rubber [11].

The chemical structures observed in the ATR-FTIR spectra of all the foam samples are not significantly different (Figure S1). They contain peaks at 3015-2970 $\mathrm{cm}^{-1}$ from C-H vibrations $\left(\mathrm{CH}_{3}\right.$ and $\left.\mathrm{CH}_{2}\right)$ and $1672 \mathrm{~cm}^{-1}$ from $\mathrm{C}=\mathrm{C}$ double bonds in the natural rubber molecule. An absorption peak between 935 and $1171 \mathrm{~cm}^{-1}$ belongs to $C-S$ stretching, which confirms crosslinking between sulphur atoms and natural rubber molecules and that the peak at $840 \mathrm{~cm}^{-1}$ is associated with $C=C$ wagging in natural rubber $[24,34,35]$.

\subsection{Physical and Chemical Elasticity}

The elasticity of rubber foam can be derived assuming that mechanical compression relates to the physical elasticity and that swollen rubber foam in a good solvent relates to the chemical elasticity. Both types of elasticity can be applied to evaluate the thermodynamic parameters in different ways.

Figure 3 shows the mechanical properties of rubber foam in two ways. First, the compression stress $(\sigma)$-strain $(\varepsilon)$ curve of rubber foam samples is presented. Rubber foam can be deformed until around 50\% strain before non-linear elastic collapse caused by the elastic buckling of cell walls occurs. The elastic collapse stress and the post-collapse behaviour depend on the open-cell structure, which shows a long flat plateau in the stressstrain curve [36]. Second, at large compression strains, the opposing walls of the cells crush together, and the cell wall material itself is compressed. This is the strain at which all the pore space has been collapsed, otherwise known as the densification regime [37]. For uncrosslinked polymer foam, the phenomenon of strain-induced crystallisation can be accounted for by these mechanical properties at high strains [38].

We found no significant differences in the macroscopic compression stress-strain curves in any foam samples (Figure 3). As discussed before, higher chemical blowing agent concentrations lowered the foam density since more gas was generated. However, the mechanical properties from the stress-strain curve were similar, indicating the heterogeneous structure of the rubber foam produced with the Dunlop method $[39,40]$. The control sample had a large cell size, and the matrix had a small cell size distribution. When the chemical blowing agent concentration was reduced, the cell size became smaller, and the cell density increased. However, the porosity percentage was only slightly different. This similarity explains why the mechanical properties of all the samples were similar. Therefore, the morphological properties of rubber foam with a heterogeneous structure are more sensitive to the concentration of the chemical blowing agent than the mechanical properties in compression mode. The mechanical properties of rubber foam depend not only on the morphological properties [41] but also on the interconnected foam matrix [33]. 
For the same polymer concentration without filler, the mechanical property (or storage modulus) of poly(methyl methacrylate) (PMMA) foam can differ with the difference of cell sizes between nanosized and microsized foams [41].

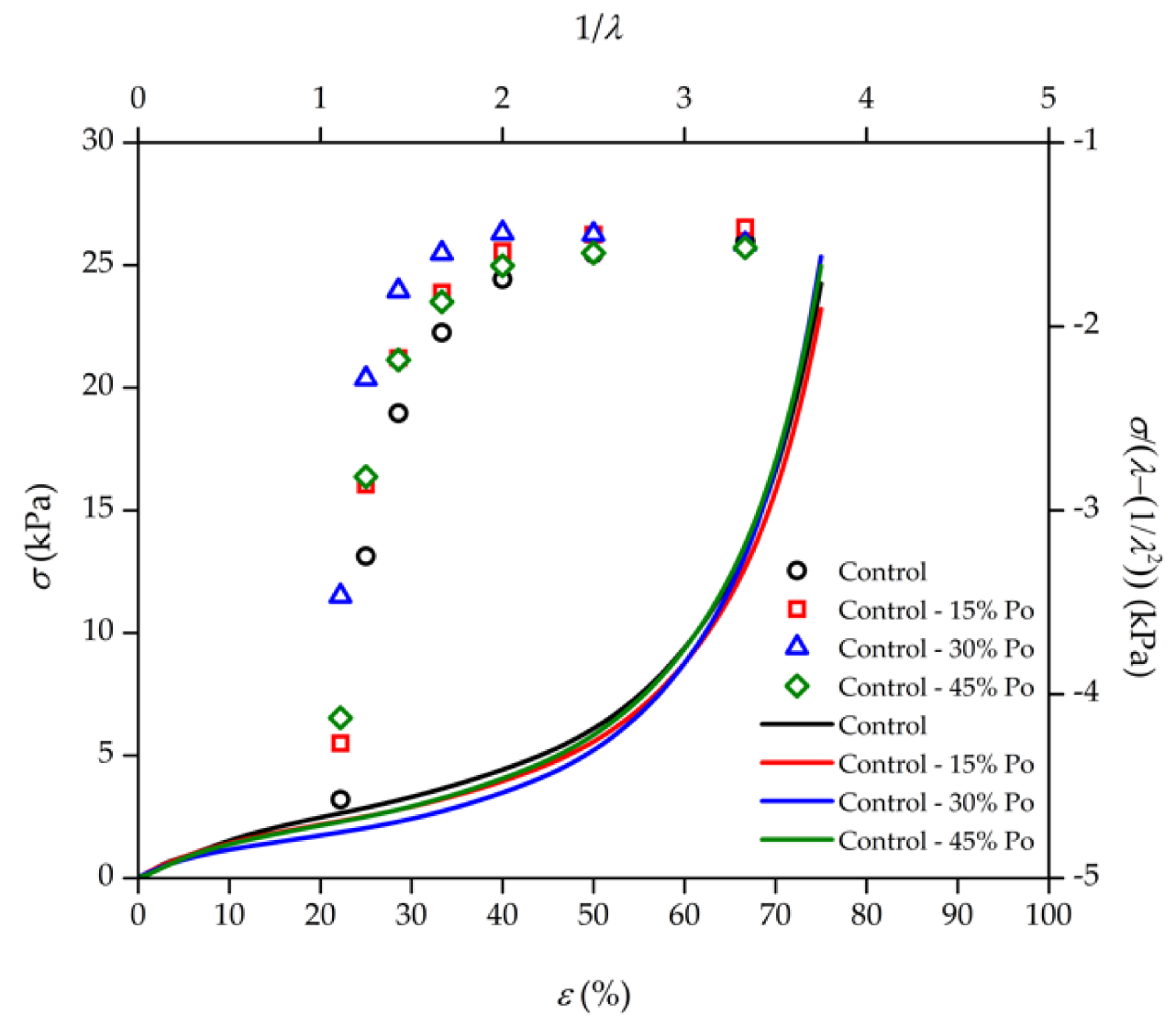

Figure 3. Results of the mechanical properties of rubber foam in two forms: (i) stress ( $\sigma)$-strain $(\varepsilon)$ curves of foam samples with various concentrations of chemical blowing agent in lines; (ii) the Mooney-Rivlin equation [17] for rubber foam in the unfilled symbols. The relative scatter on the results is estimated to be about $5 \%$.

Figure 3 also presents the compression curves based on the extension of the MooneyRivlin equation [17], which is why our compression result has the opposite trend to the Mooney-Rivlin results. From the Mooney-Rivlin equation, we found similar crosslinking densities for all foam samples at high compression strains (or high $1 / \lambda$ ), while, at low compression strains (or low $1 / \lambda$ ), the control sample with the highest amounts of chemical blowing agent had the lowest stress compared to that of the foam samples with lower amounts of the chemical blowing agent. This is remarkably interesting considering the difference in compression between low and high strains, which is related to the difference between morphological structures. At low strain, the NR foam cells are buckled, whereas the foam cells are completely collapsed at high strains. Therefore, we can find the different mechanical properties of NR foams based on the Mooney-Rivlin equation [17] at low strain, but this mechanical property of NR foams is quite similar at high strains.

Table 3 presents the $C_{1}$ and $C_{2}$ of our crosslinked NR foam samples in compression mode based on the Mooney-Rivlin equation [17]. Generally, $2 C_{1}$ relates to the shear modulus $(G)$, as in Equations (4) and (5), and $2 C_{2}$ relates to the shear modulus of polymer entanglement $\left(G_{e}\right)$. We found that our $C_{1}$ is in reasonable agreement with the literature reviews [42,43], confirming that crosslinked solid rubber possesses a high shear modulus and high $C_{1}$ compared to uncrosslinked solid rubber. The ratio $C_{2} / C_{1}$ from our result is 
in good agreement with the literature [42,43]. The shear modulus $(G)$ can be written as follows:

$$
\begin{gathered}
G=f_{\mathrm{c}} G_{\mathrm{c}}+\varnothing(\lambda) G_{\mathrm{e}} \\
\varnothing(\lambda)=\frac{1}{\lambda}
\end{gathered}
$$

where $f_{\mathrm{c}}$ is the function of network defects, $G_{\mathrm{c}}$ is the shear modulus of the polymer network, and $G_{e}$ is the shear modulus of polymer entanglement.

Table 3. Constant values $C_{1}$ and $C_{2}$ from the Mooney-Rivlin equation [17] at different compression or extension limits $(\lambda)$ of various rubber samples.

\begin{tabular}{ccccccc}
\hline Type of Rubber & Test & $\lambda$ & $\boldsymbol{C}_{\mathbf{1}}$ & $\boldsymbol{C}_{\mathbf{2}}$ & $\boldsymbol{C}_{\mathbf{2}} / \boldsymbol{C}_{\mathbf{1}}$ & Reference \\
\hline Crosslinked NR foam & Compression & $<1$ & 1.1809 & 0.1330 & 0.113 & - \\
Uncrosslinked solid NR & Extension & $1 \leq \lambda \leq 2$ & 1.7725 & 2.7042 & 1.526 & {$[42]$} \\
Crosslinked solid PDMS & Extension & $<1$ & 2.91 & 1.98 & 0.682 & {$[43]$} \\
\hline
\end{tabular}

The chemical elasticity can be studied using the crosslinking density and volume fraction of the rubber of various foam samples, which has only small differences (Table 4) because of the effect of the chemical blowing agent on the morphological properties of the foams. These results relate to the change in the Gibbs free energy $(\Delta G)$ in negative values and the change of entropy $(\Delta S)$ in positive values, which correspond to the spontaneous thermodynamic favourability.

Table 4. The volume fraction of rubber from the swelling test and thermodynamic parameters $(\Delta G$ and $\Delta S$ ) from the Flory-Huggins equation [21,22].

\begin{tabular}{cccc}
\hline Sample & $\begin{array}{c}\text { Volume Fraction of } \\
\text { Rubber } \\
\left(V_{\mathbf{r}} \pm \mathbf{0 . 0 0 1} \%\right)\end{array}$ & $\Delta G(\mathbf{J} / \mathbf{m o l})$ & $\Delta S(\mathbf{J} / \mathbf{m o l} . \mathbf{K})$ \\
\hline Control & 0.2594 & -36.3233 & 0.1218 \\
Control - 15\% Po & 0.2574 & -35.6039 & 0.1194 \\
Control - 30\% Po & 0.2540 & -34.3942 & 0.1154 \\
Control - 45\% Po & 0.2524 & -33.8061 & 0.1134 \\
\hline
\end{tabular}

Consideration of the thermodynamics of the process of extension elasticity is fundamental to developing the statistical theory [44-46]. The molecular mechanisms corresponding to rubber elasticity have been proposed in previous works on the statistical theories that explain the mechanical properties of rubbers [47-49]. These works developed a good basic understanding of rubber elasticity. Next, advanced theories were developed to explain the effect of entangled chains in rubber networks while still agreeing with the statistical theory of rubber elasticity $[44,50,51]$. However, we applied this theory for our rubber foams in compression mode. On the simplest level, we propose that the deformation in compression is accompanied by a decrease in entropy $(S)$ with an increase in internal energy $(U)$ of the molecular network. Figures 4-7 present the evolution of compression force as a function of temperature for each compression strain of the control sample, control - 15\% Po sample, control - 30\% Po sample, and control - $45 \%$ Po sample, respectively. We found that the compression force of the rubber foam increases with increasing compression strain. The compression force also tends to decrease with increasing temperature at a given strain. Meanwhile, the compression force slope and the temperature curve tend to decrease at a higher compression strain because of a reduction of the degree of freedom of rubber molecules in the foam sample, which is related to the reduction of entropy. Thus, there is an entropy decrease on compression and an increase on retraction, except

i. at very low deformations, below about $10 \%$, where a so-called thermoplastic inversion is observed due to thermal expansion obscuring the entropy effect [44]; 
ii. at large deformations, where high degrees of orientation and crystallisation may occur [33].

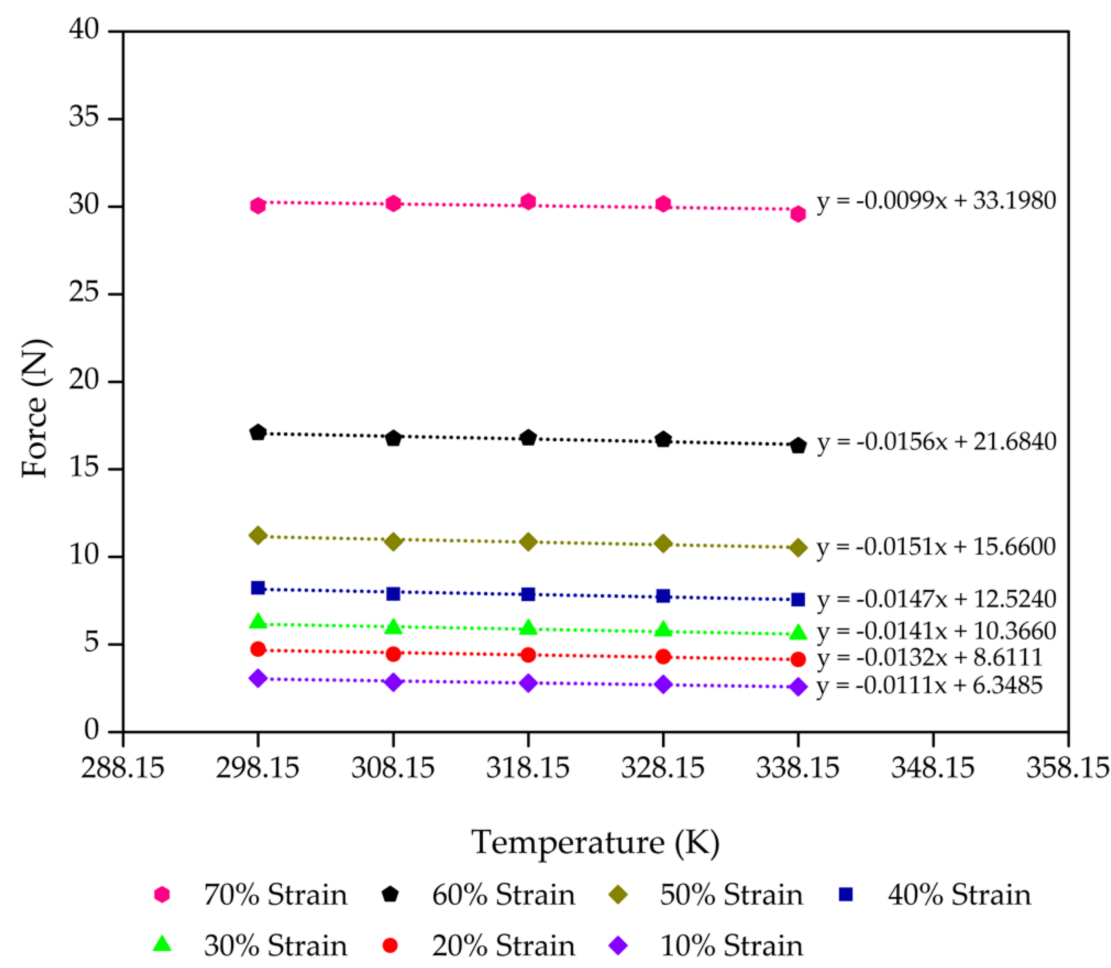

Figure 4. Compression force as a function of the temperature of the control sample from $10 \%$ to $70 \%$ compression strain with a minimum linear regression $\left(\mathrm{R}^{2}\right)=0.9$ at each strain. The scatter on the results is on the order of the size of the data points.

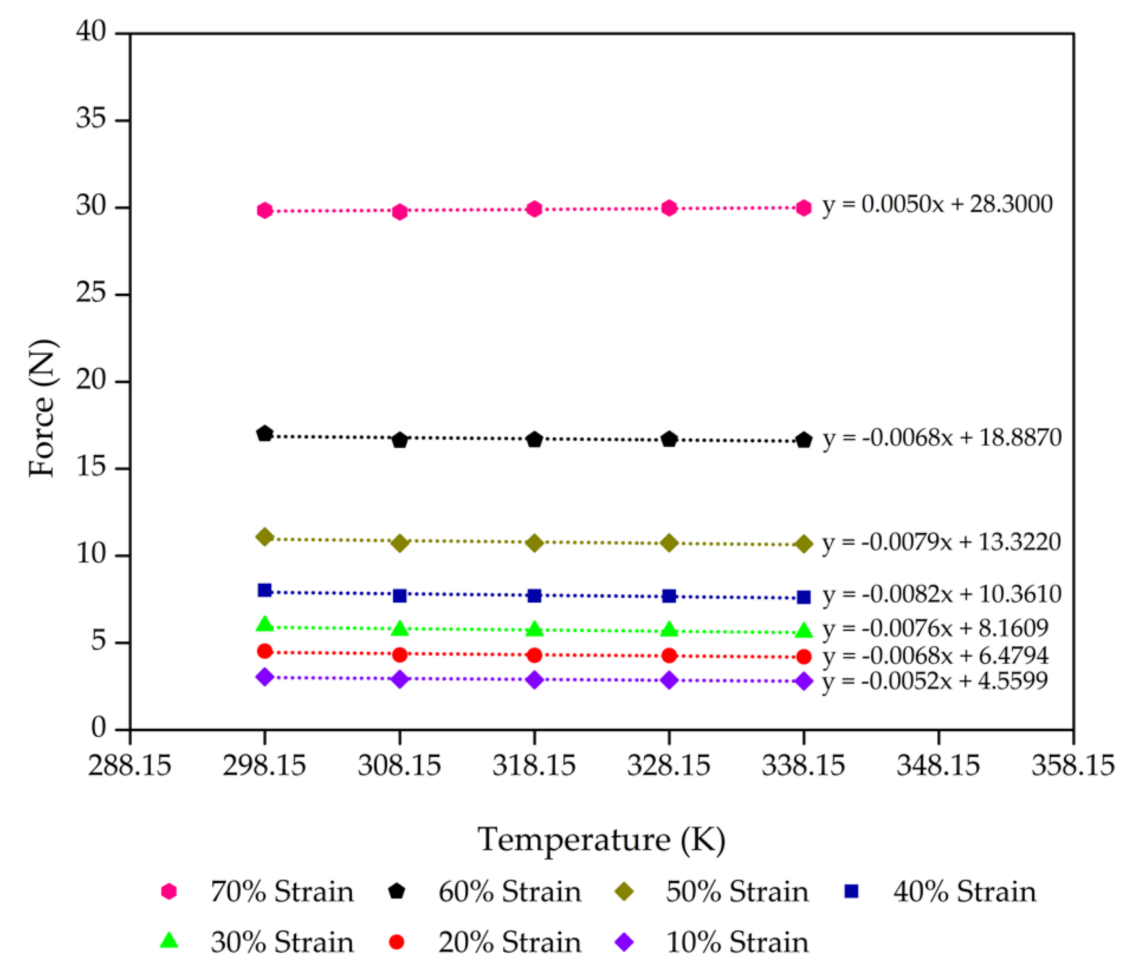

Figure 5. Compression force as a function of the temperature of the control - 15\% Po sample from $10 \%$ to $70 \%$ compression strain with a minimum linear regression $\left(R^{2}\right)=0.9$ at each strain. The scatter on the results is on the order of the size of the data points. 


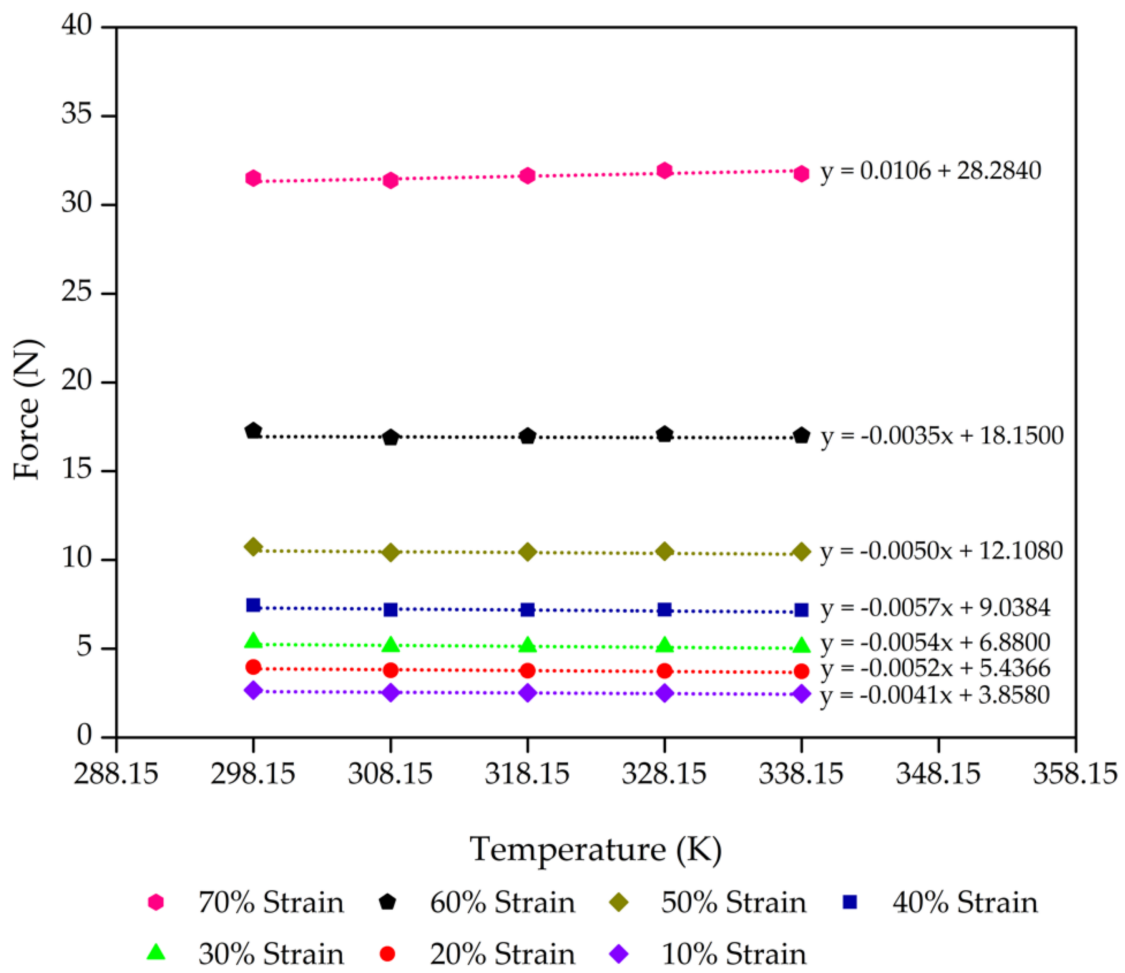

Figure 6. Compression force as a function of the temperature of the control - 30\% Po sample from $10 \%$ to $70 \%$ compression strain with a minimum linear regression $\left(R^{2}\right)=0.9$ at each strain. The scatter on the results is on the order of the size of the data points.

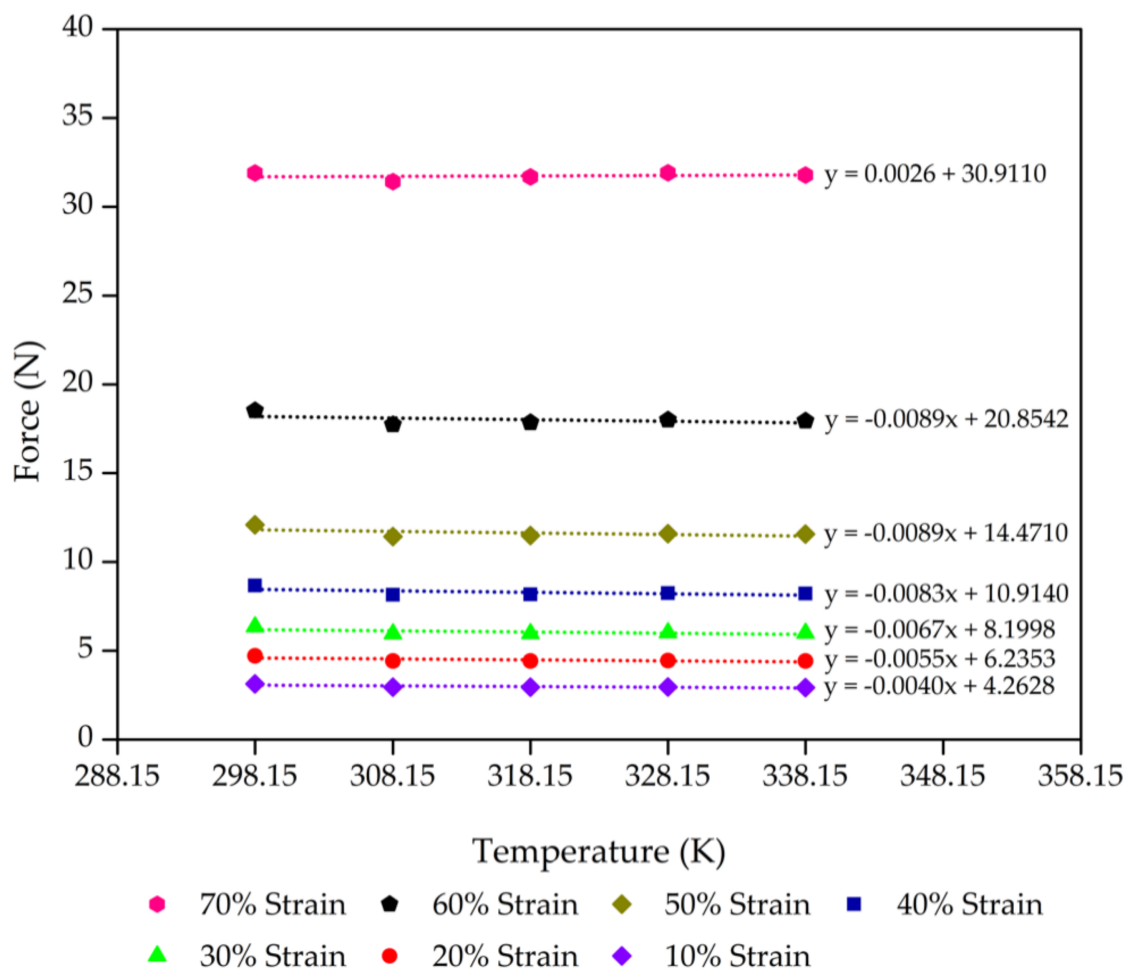

Figure 7. Compression force as a function of the temperature of the control - $45 \%$ Po sample from $10 \%$ to $70 \%$ compression strain with a minimum linear regression $\left(R^{2}\right)=0.9$ at each strain. The scatter on the results is on the order of the size of the data points. 
Based on the thermodynamics, the physical elasticity during the compression deformation of rubber molecules corresponds to the changes of internal energy force $\left(F_{\mathrm{u}}\right)$ and entropy force $\left(F_{\mathrm{s}}\right)$; thus, the compression force $(F)$ is the summation of the internal energy force and the entropy force [44]. Table 5 shows that $F_{\mathrm{u}}$ and $F$ for all the samples increase with increasing compression strain or decreasing compression limit, which is in reasonable agreement. However, the $F_{\mathrm{u}} / F$ values of various crosslinked rubber foams in this study range from 0.7 to 1 .2. From the perspective of the available literature, the $F_{\mathrm{u}} / F$ values of the crosslinked natural rubber foam in the compression mode are in the range of $0.6-0.8$ [33], while the foam density of that study was lower than that in our study. For the uncrosslinked solid natural rubber in extension mode, the $F_{\mathrm{u}} / F$ values in the literature are in the range of 0.1-0.2 [44]. These different $F_{\mathrm{u}} / F$ ratios should be different for different rubber networks, characterisation methods, and the formulas of compounded rubbers. After taking those factors into account, we can express the relationship between the $F_{\mathrm{u}} / F$ ratios and the compression limit of rubber foam, as shown in Figure 8. This relationship is in good agreement with natural rubber foam reinforced by silica [33]. Our natural rubber foams with various concentrations of chemical blowing agent represent a similar degree of freedom of rubber molecules at different compression limits, indicating the stability of the degree of freedom of rubber chains at different compression limits.

Table 5. The ratio of the internal energy force $\left(F_{\mathrm{u}}\right)$ to the compression force $(F)$ of various foam samples for different compression limits at $298.15 \mathrm{~K}$.

\begin{tabular}{|c|c|c|c|c|}
\hline Foam Sample & $\begin{array}{l}\text { Compression } \\
\text { Limit }(\lambda)\end{array}$ & $F_{\mathrm{u}}( \pm 5 \% \mathrm{~N})$ & $\begin{array}{c}F @ 298.15 \mathrm{~K} \\
( \pm 5 \% \mathrm{~N})\end{array}$ & $F_{\mathbf{u}} / F$ \\
\hline \multirow[t]{7}{*}{ Control } & 0.9 & 6.35 & 9.66 & 0.6573 \\
\hline & 0.8 & 8.61 & 12.55 & 0.6863 \\
\hline & 0.7 & 10.37 & 14.57 & 0.7115 \\
\hline & 0.6 & 12.52 & 16.91 & 0.7408 \\
\hline & 0.5 & 15.66 & 20.16 & 0.7767 \\
\hline & 0.4 & 21.68 & 26.34 & 0.8234 \\
\hline & 0.3 & 33.20 & 36.15 & 0.9183 \\
\hline \multirow[t]{7}{*}{ Control - 15\% Po } & 0.9 & 4.56 & 6.11 & 0.7463 \\
\hline & 0.8 & 6.48 & 8.51 & 0.7617 \\
\hline & 0.7 & 8.16 & 10.43 & 0.7827 \\
\hline & 0.6 & 10.36 & 12.81 & 0.8091 \\
\hline & 0.5 & 13.32 & 15.68 & 0.8498 \\
\hline & 0.4 & 18.89 & 20.91 & 0.9031 \\
\hline & 0.3 & 28.30 & 26.81 & 1.0556 \\
\hline \multirow[t]{7}{*}{ Control - $30 \%$ Po } & 0.9 & 3.72 & 4.85 & 0.7663 \\
\hline & 0.8 & 5.39 & 6.91 & 0.7800 \\
\hline & 0.7 & 6.88 & 8.52 & 0.8075 \\
\hline & 0.6 & 8.99 & 10.69 & 0.8410 \\
\hline & 0.5 & 11.90 & 13.27 & 0.8966 \\
\hline & 0.4 & 17.46 & 17.97 & 0.9718 \\
\hline & 0.3 & 26.81 & 22.31 & 1.2018 \\
\hline \multirow[t]{7}{*}{ Control - $45 \%$ Po } & 0.9 & 4.26 & 5.46 & 0.7814 \\
\hline & 0.8 & 6.24 & 7.88 & 0.7918 \\
\hline & 0.7 & 8.20 & 10.20 & 0.8041 \\
\hline & 0.6 & 10.91 & 13.39 & 0.8152 \\
\hline & 0.5 & 14.47 & 17.12 & 0.8450 \\
\hline & 0.4 & 20.85 & 23.51 & 0.8871 \\
\hline & 0.3 & 30.91 & 30.14 & 1.0257 \\
\hline
\end{tabular}




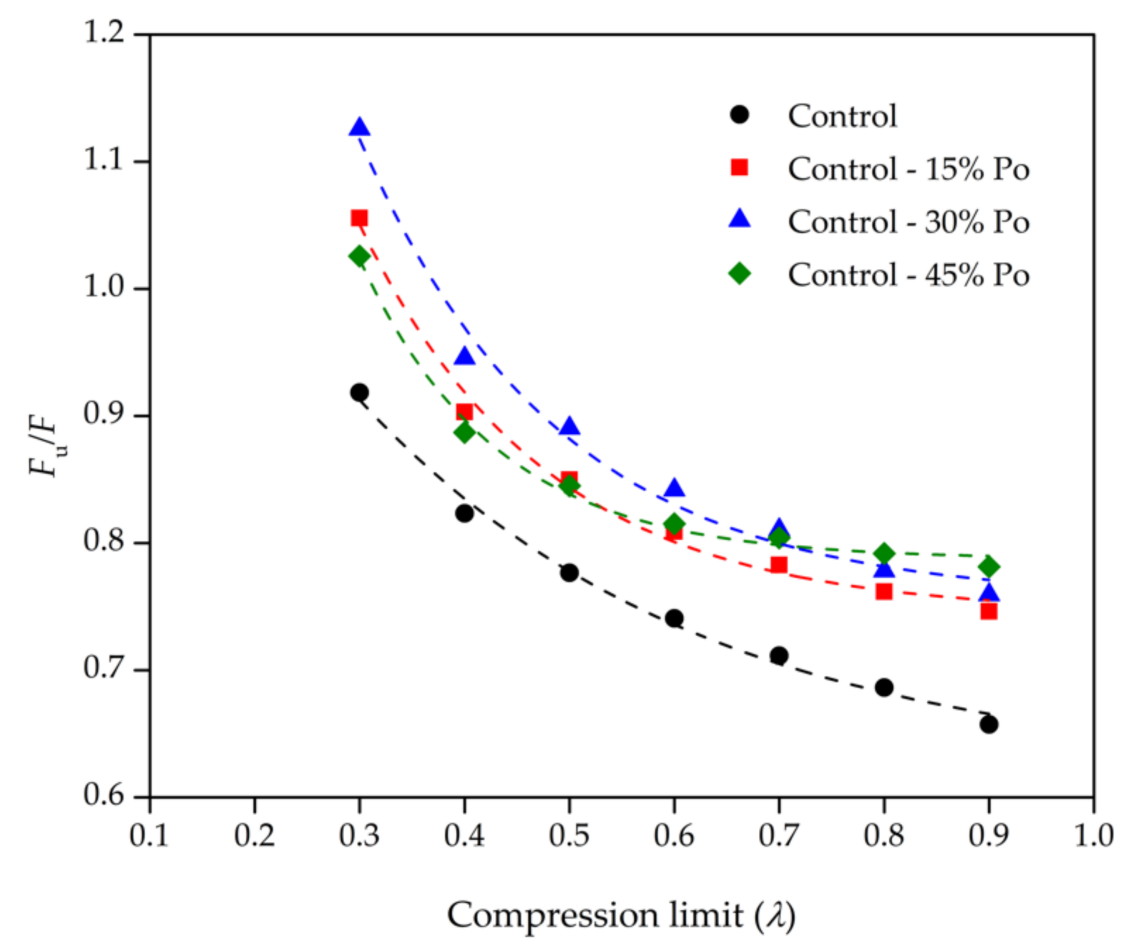

Figure 8. Ratios of the internal energy force $\left(F_{\mathrm{u}}\right)$ to the compression force $(F)$ as a function of the compression limit $(\lambda)$ for various rubber foams. The scatter on the results is on the order of the size of the data points.

\section{Conclusions}

Natural rubber foams were produced with different formulations by varying the chemical blowing agent concentration in the compounded latex. The morphological properties of rubber foam were very sensitive to the amount of the chemical blowing agent compared to the response of the physical elasticity. When the chemical blowing agent of rubber foam was decreased by $45 \%$, the average cell size was also decreased to around $50 \%$, while the cell density increased by around $800 \%$. The average cell size, porosity and cell density of the rubber foams varied according to the concentration of the chemical blowing agent, whereas the compression of the rubber foams was similar for all samples. However, we measured a different mechanical property for the NR foam using the Mooney-Rivlin equation at low strain. Therefore, the mechanical properties of rubber foam depend on the morphological structure, the formulation of the compounded latex and the testing method. The ratio of the internal energy force $\left(F_{\mathrm{u}}\right)$ to the compression force $(F)$ of this work aligns with those in previous literature reviews. The chemical elasticity from crosslinked rubber networks can be used to calculate the thermodynamic parameters $\Delta G$ and $\Delta S$. This study is a semi-empirical model for controlling the morphological properties of rubber foams to obtain different foam structures while retaining similar mechanical properties, especially compression. One can imagine tuning the structure of foam insulation or pillows to control the airflow to obtain the optimum mechanical property for the intended use.

Supplementary Materials: The following are available online at https:/ /www.mdpi.com/article/10 .3390 / polym13071091/s1, Table S1: Formulas of rubber foams at various chemical blowing agents, Figure S1: ATR-FTIR spectrum of control foam sample at $500-4000 \mathrm{~cm}^{-1}$, the other foam samples with reducing of chemical blowing agent represent the same ATR-FTIR spectrum with the control foam sample. 
Author Contributions: Conceptualisation, W.S.; methodology, W.S.; software, S.S., validation, S.P., J.W.-e. and W.S., formal analysis, S.S., investigation, S.P., J.W.-e. and W.S.; resources, W.S., data curation, S.S., writing —original draft preparation, S.S., writing—review and editing, S.P., J.W.-e. and W.S., visualisation, S.S. and W.S., supervision, W.S., project administration, W.S., funding acquisition, W.S. All authors have read and agreed to the published version of the manuscript.

Funding: This research received no external funding.

Institutional Review Board Statement: the study did not involve humans or animals.

Informed Consent Statement: the study did not involve humans.

Data Availability Statement: The data that support the findings of this study are available from the corresponding author upon reasonable request.

Acknowledgments: This research is supported in part by the Graduate Program Scholarship from The Graduate School, Kasetsart University.

Conflicts of Interest: The authors declare no conflict of interest. The funders had no role in the design of the study; in the collection, analyses, or interpretation of data; in the writing of the manuscript, or in the decision to publish the results.

\section{References}

1. Madge, E.W. Latex foam Rubber; Maclaren and Sons: London, UK, 1962.

2. Blackley, D.C. Polymer Latices: Science and Technology Volume 3: Applications of Latices; Springer: Heidelberg/Berlin, Germany, 1997.

3. Roslim, R.; Hashim, M.Y.A.; Augurio, P.T. Natural latex foam. J. Eng. Sci. 2012, 8, 15-27.

4. Kim, J.H.; Choi, K.C.; Yoon, J.M. The foaming characteristics and physical properties of natural rubber foams: Effects of carbon black content and foaming pressure. J. Ind. Eng. Chem. 2006, 12, 795-801.

5. Murphy, E.A. Recent progress in latex technology. Ind. Eng. Chem. 1952, 44, 756-762. [CrossRef]

6. British Rubber Development Board. Natural Rubber Latex and Its Applications: The Preparation of Latex Foam Products; British Rubber Development Board: London, UK, 1954.

7. Ramasamy, S.; Ismail, H.; Munusamy, Y. Effect of rice husk powder on compression behavior and thermal stability of natural rubber latex foam. Bioresources 2013, 8, 4258-4269. [CrossRef]

8. Wilbanks, A.; Oxford, N.; Mil, D. Textiles for Residential and Commercial Interiors, 4th ed.; Bloomsbury Publishing Inc.: New York, NY, USA, 2015.

9. Eaves, D. Handbook of Polymer Foams; Smithers Rapra Publishing: Shrewsbury, UK, 2004.

10. Syahrin, S.M.; Zunaida, Z.; Hakimah, O.; Nuraqmar, S.M.S. Effect of blowing agent on compression and morphological properties of natural rubber latex foam. AIP Conf. Proc. 2020, 2267, 020037.

11. Najib, N.N.; Ariff, Z.M.; Manan, N.A.; Bakar, A.A.; Sipuat, C.S. Effect of blowing agent concentration on cell morphology and impact properties of natural rubber foam. J. Phys. Sci. 2009, 20, 13-25.

12. Chen, Y.; Das, R.; Battley, M. Effects of cell size and cell wall thickness variations on the stiffness of closed-cell foams. Int. J. Solids Struct. 2015, 52, 150-164. [CrossRef]

13. Wang, G.; Zhao, J.; Wang, G.; Mark, L.H.; Park, C.B.; Zhao, G. Low-density and structure-tunable microcellular PMMA foams with improved thermal-insulation and compressive mechanical properties. Eur. Polym. J. 2017, 95, 382-393. [CrossRef]

14. Lin, G.; Zhang, X.-J.; Liu, L.; Zhang, J.-C.; Chen, Q.-M.; Zhang, L.-Q. Study on microstructure and mechanical properties relationship of short fibers/rubber foam composites. Eur. Polym. J. 2004, 40, 1733-1742. [CrossRef]

15. Schneider, C.A.; Rasband, W.S.; Eliceiri, K.W. NIH image to ImageJ: 25 years of image analysis. Nat. Methods 2012, 9, 671-675. [CrossRef]

16. Forest, C.; Chaumont, P.; Cassagnau, P.; Swoboda, B.; Sonntag, P. Polymer nano-foams for insulating applications prepared from $\mathrm{CO}_{2}$ foaming. Prog. Polym. Sci. 2015, 41, 122-145. [CrossRef]

17. Fukahori, Y.; Seki, W. Molecular behaviour of elastomeric materials under large deformation: 1 . Re-evaluation of the MooneyRivlin plot. Polymer 1992, 33, 502-508. [CrossRef]

18. Flory, P.J.; Rehner, J. Statistical mechanics of cross-linked polymer networks II. Swelling. J. Chem. Phys. 1943, 11, 521-526. [CrossRef]

19. Croll, S.G. Application of the Flory-Rehner equation and the Griffith fracture criterion to paint stripping. J. Coat. Technol. Res. 2009, 7, 49-55. [CrossRef]

20. Tangboriboon, N.; Rortchanakarn, S.; Petcharoen, K.; Sirivat, A. Effects of foaming agents and eggshell calcium carbonate $\left(\mathrm{CaCO}_{3}\right)$ filler on natural rubber foam physical-thermal-Mechanical properties. J. Rubber Res. 2016, 19, 71-96.

21. Pojanavaraphan, T.; Magaraphan, R. Prevulcanized natural rubber latex/clay aerogel nanocomposites. Eur. Polym. J. 2008, 44, 1968-1977. [CrossRef]

22. Ghari, H.S.; Jalali-Arani, A. Nanocomposites based on natural rubber, organoclay and nano-calcium carbonate: Study on the structure, cure behavior, static and dynamic-mechanical properties. Appl. Clay Sci. 2016, 119, 348-357. [CrossRef] 
23. Smitthipong, W.; Nardin, M.; Schultz, J.; Suchiva, K. Adhesion and self-adhesion of rubbers, crosslinked by electron beam irradiation. Int. J. Adhes. Adhes. 2007, 27, 352-357. [CrossRef]

24. Suksup, R.; Sun, Y.; Sukatta, U.; Smitthipong, W. Foam rubber from centrifuged and creamed latex. J. Polym. Eng. 2019, 39, 336-342. [CrossRef]

25. Phomrak, S.; Nimpaiboon, A.; Newby, B.-M.Z.; Phisalaphong, M. Natural rubber latex foam reinforced with micro- and nanofibrillated cellulose via Dunlop method. Polymers 2020, 12, 1959. [CrossRef]

26. Wang, S.; Ameli, A.; Shaayegan, V.; Kazemi, Y.; Huang, Y.; Naguib, H.E.; Park, C.B. Modelling of rod-like fillers' rotation and translation near two growing cells in conductive polymer composite foam processing. Polymers 2018, 10, 216. [CrossRef]

27. Timpano, C.; Abdoli, H.; Leung, S.N.; Melenka, G.W. Characterization of open-cellular polymeric foams using micro-computed tomography. Polymer 2020, 202, 122628. [CrossRef]

28. Quell, A.; de Bergolis, B.; Drenckhan, W.; Stubenrauch, C. How the locus of initiation influences the morphology and the pore connectivity of a monodisperse polymer foam. Macromolecules 2016, 49, 5059-5067. [CrossRef]

29. Williams, J.M.; Wrobleski, D.A. Spatial distribution of the phases in water-in-oil emulsions. Open and closed microcellular foams from crosslinked polystyrene. Langmuir 1988, 4, 656-662. [CrossRef]

30. Mantaranon, N.; Chirachanchai, S. Polyoxymethylene foam: From an investigation of key factors related to porous morphologies and microstructure to the optimization of foam properties. Polymer 2016, 96, 54-62. [CrossRef]

31. Krause, B.; Mettinkhof, R.; van der Vegt, N.F.A.; Wessling, M. Microcellular foaming of amorphous high-Tg polymers using carbon dioxide. Macromolecules 2001, 34, 874-884. [CrossRef]

32. Kim, Y.; Park, C.B.; Chen, P.; Thompson, R.B. Towards maximal cell density predictions for polymeric foams. Polymer 2011, 52, 5622-5629. [CrossRef]

33. Prasopdee, T.; Smitthipong, W. Effect of fillers on the recovery of rubber foam: From theory to applications. Polymers 2020, 12, 2745. [CrossRef] [PubMed]

34. Tanrattanakul, V.; Chumeka, W. Effect of potassium persulfate on graft copolymerization and mechanical properties of cassava starch/natural rubber foams. J. Appl. Polym. Sci. 2010, 116, 93-105. [CrossRef]

35. Agrebi, F.; Ghorbel, N.; Bresson, S.; Abbas, O.; Kallel, A. Study of nanocomposites based on cellulose nanoparticles and natural rubber latex by ATR/FTIR spectroscopy: The impact of reinforcement. Polym. Compos. 2019, 40, 2076-2087. [CrossRef]

36. Jin, F.-L.; Zhao, M.; Park, M.; Park, S.-J. Recent trends of foaming in polymer processing: A review. Polymers 2019, 11, 953. [CrossRef] [PubMed]

37. Messinger, R.J.; Marks, T.G.; Gleiman, S.S.; Milstein, F.; Chmelka, B.F. Molecular origins of macroscopic mechanical properties of elastomeric organosiloxane foams. Macromolecules 2015, 48, 4835-4849. [CrossRef]

38. Rizvi, A.; Tabatabaei, A.; Vahedi, P.; Mahmood, S.H.; Park, C.B. Non-crosslinked thermoplastic reticulated polymer foams from crystallization-induced structural heterogeneities. Polymer 2018, 135, 185-192. [CrossRef]

39. Hui Mei, E.L.; Singh, M. The Dunlop process in natural rubber latex foam. Malays. Rubber Dev. Technol. 2010, 10, $23-26$.

40. Bashir, A.S.M.; Manusamy, Y.; Chew, T.L.; Ismail, H.; Ramasamy, S. Mechanical, thermal, and morphological properties of (eggshell powder)-filled natural rubber latex foam. J. Vinyl Addit. Technol. 2017, 23, 3-12. [CrossRef]

41. Notario, B.; Pinto, J.; Rodríguez-Pérez, M.A. Towards a new generation of polymeric foams: PMMA nanocellular foams with enhanced physical properties. Polymer 2015, 63, 116-126. [CrossRef]

42. Mangan, R.; Destrade, M.; Saccomandi, G. Strain energy function for isotropic non-linear elastic incompressible solids with linear finite strain response in shear and torsion. Extreme Mech. Lett. 2016, 9, 204-206. [CrossRef]

43. Kawamura, T.; Urayama, K.; Kohjiya, S. Multiaxial deformations of end-linked poly(dimethylsiloxane) networks 5. Revisit to Mooney-Rivlin approach to strain energy density function. Nihon Reoroji Gakkaishi 2003, 31, 213-217. [CrossRef]

44. Treloar, L.R.G. The Physics of Rubber Elasticity; Oxford University Press: New York, NY, USA, 1975.

45. Hiemenz, P.C.; Lodge, T.P. Polymer Chemistry, 2nd ed.; CRC Press: Boca Raton, FL, USA, 2007.

46. Rubinstein, M.; Colby, R.H. Polymer Physics; Oxford University Press: Oxford, UK, 2003.

47. Wall, F.T.; Flory, P.J. Statistical thermodynamics of rubber elasticity. J. Chem. Phys. 1951, 19, 1435-1439. [CrossRef]

48. Deam, R.T.; Edwards, S.F. The theory of rubber elasticity. Philos. Trans. R. Soc. A 1976, 280, 317-353.

49. Flory, P.J. Molecular theory of rubber elasticity. Polymer 1979, 20, 1317-1320. [CrossRef]

50. Erman, B.; Mark, J.E. The molecular basis of rubberlike elasticity. In Science and Technology of Rubber, 3rd ed.; Mark, J.E., Erman, B., Eirich, F.R., Eds.; Academic Press: London, UK, 2005.

51. Mark, J.E.; Erman, B. Rubberlike Elasticity: A Molecular Primer, 2nd ed.; Cambridge University Press: Cambridge, UK, 2007. 